\title{
Is There a Relation between ABO Blood Groups and Clinical Outcome in Patients with Pemphigoid? A Case-Control Study
}

\author{
Sedigheh Bakhtiari, ${ }^{1}$ Parviz Toosi, ${ }^{2}$ Somayyeh Azimi, ${ }^{1,3}$ Nafiseh Esmaili, ${ }^{4}$ \\ Ali Montazami, ${ }^{5}$ and Nasrin Rafieian ${ }^{6}$ \\ ${ }^{1}$ Oral Medicine Department, Dental School, Shahid Beheshti University of Medical Sciences, Tehran, Iran \\ ${ }^{2}$ Skin Research Center, Tehran University of Medical Sciences, Tehran, Iran \\ ${ }^{3}$ The International Research Collaborative - Oral Health and Equity, School of Anatomy, Physiology and Human Biology, \\ University of Western Australia, Crawley, WA 6009, Australia \\ ${ }^{4}$ Skin Research Center, Shahid Beheshti University of Medical Sciences, Tehran, Iran \\ ${ }^{5}$ Shahid Beheshti University of Medical Sciences, Tehran, Iran \\ ${ }^{6}$ Department of Oral Medicine, Faculty of Dentistry, Alborz University of Medical Sciences, Karaj, Iran
}

Correspondence should be addressed to Nasrin Rafieian; rafieiann@yahoo.com

Received 29 November 2015; Revised 17 March 2016; Accepted 30 March 2016

Academic Editor: Iris Zalaudek

Copyright (C) 2016 Sedigheh Bakhtiari et al. This is an open access article distributed under the Creative Commons Attribution License, which permits unrestricted use, distribution, and reproduction in any medium, provided the original work is properly cited.

Background. Relationship between blood groups and dermatologic diseases remains controversial and was not yet fully elucidated nor explained clearly. The aim of this study was to examine if any relation exists between different types of pemphigoid diseases and ABO blood group. Methods. In this case-control study, 159 pemphigoid patients and 152 healthy matched-controls were evaluated. All blood group (including Rh status) data for the study was obtained from the hospital medical records. Statistical comparisons were completed with chi-square test and logistic regression. Results. Blood group "O" was found in 32.9\% of patients and 38.2\% of control group. Blood group " $\mathrm{A}$ " was found among $30.8 \%$ of patients and $34.2 \%$ of control group, while group "B" was reported in $27.4 \%$ of cases and $21.1 \%$ of controls and " $A B$ " was identified among $8.9 \%$ of patients and $6.6 \%$ of control group. $84.9 \%$ of patients were $\mathrm{Rh}$ positive, while in the control group $86.2 \%$ of patients were Rh positive. No significant differences were found regarding ABO blood groups $(P=0.46)$ or $\mathrm{Rh}(P=0.76)$ between pemphigoid patients and control group. Also, older females had the higher risk of developing bullous pemphigoid. Conclusion. We found no relationship between ABO blood groups and pemphigoid disease.

\section{Introduction}

Pemphigoid is a subepithelial bullous disease that is characterized by an autoimmune reaction that weakens the basement membrane. There are 3 types of pemphigoid. Bullous pemphigoid (BP) is the most common subepithelial blistering disease, which is mainly observed in adults over 60 years old [1]. Mucous membrane pemphigoid (MMP), previously called cicatricial pemphigoid (CP), is a subtype of disease that primarily affects mucous membrane of patients over 50 years old and causes mucosal ulceration and scars [1-3]. Another type of pemphigoid is pemphigoid gestationis (PG) that refers to pregnancy. The cutaneous hallmark of pemphigoid is tense blisters that occur on the arms, legs, abdomen, and mucous membranes. Oral lesions are also observed in pemphigoid diseases that are similar to pemphigus, which are smaller and less painful and extensive labial involvement is not observed. The disease is sometimes self-limiting but treatment is necessary $[2,3]$.

Blood groups as a hematological marker have been assessed in several studies. Genetic factors such as blood group antigens may affect the risk, severity, and development of some medical conditions. The association between blood groups and different diseases such as various malignancies, peptic ulcer, infection, diabetes mellitus, dermatologic disease, heart disease, dental caries, and infectious disease had been studied with different results [4-7]. Some studies have shown increased related risks of some diseases. For example, 
TABLE 1: Demographic characteristic of participants.

\begin{tabular}{lcccc}
\hline Type & Age & Male (\%) & Female (\%) & Total (\%) \\
\hline Mucous membrane pemphigoid & $57.6 \pm 13.9$ & $5(71.4 \%)$ & $2(28.6 \%)$ & $7(100 \%)$ \\
Bullous pemphigoid & $68.3 \pm 17.9$ & $66(45.2 \%)$ & $80(54.8 \%)$ & $146(100 \%)$ \\
Pemphigoid gestationis & $31 \pm 6.7$ & 0 & $6(100 \%)$ & $6(100 \%)$ \\
Control group & $54.1 \pm 13.4$ & $86(56.6 \%)$ & $66(43.4 \%)$ & $152(100 \%)$ \\
\hline
\end{tabular}

TABLE 2: Distribution of patients based on the site of involvement.

\begin{tabular}{lcccc}
\hline Group & Oral lesion & Cutaneous lesion & Oral \& cutaneous lesions & Total \\
\hline Mucous membrane pemphigoid & $1(14.3 \%)$ & $1(14.3 \%)$ & $5(71.4 \%)$ & $7(100 \%)$ \\
Bullous pemphigoid & 0 & $109(74.7 \%)$ & $37(25.3 \%)$ & $146(100 \%)$ \\
Pemphigoid gestationis & 0 & $6(100 \%)$ & 0 & $6(100 \%)$ \\
\hline
\end{tabular}

the association between $\mathrm{ABO}$ groups with several malignancies, hypercholesterolemia, thrombosis, myocardial infarction, duodenal ulcer, infections, and autoimmune diseases is reported [8]. Also, Mortazavi et al. [9] found that squamous cell carcinoma (SCC) has been more common in blood group B. Moreover, case-control studies have reproducibly showed significant associations of $\mathrm{ABO}$ blood group and particular HLA antigens with various human diseases. These were mainly autoimmune disorders such as pemphigus vulgaris, type 1 diabetes, multiple sclerosis, rheumatoid arthritis, psoriasis, and celiac disease [10]. Some studies evaluated the relation between blood group and pemphigus disease [8, 10-15]; for instance, Valikhani et al. [11] could not find any relation between blood groups $\mathrm{ABO}$ and $\mathrm{Rh}$ factor with pemphigus disease among the Iranian population. Also Tirado-Sánchez and Ponce-Olivera [15] concluded the nonexistent relationship between $\mathrm{ABO}$ and Rhesus blood groups and pemphigus vulgaris. To the best of our knowledge, we could not find any study to evaluate the association between blood groups and pemphigoid. Since distribution of ABO genes is different among ethnic and social groups, the aim of this study was to determine any linkage between $\mathrm{ABO}$ and pemphigoid in the Iranian population.

\section{Materials and Methods}

In this case-control study, all patients with a history of pemphigoid that were referred to Razi Hospital Tehran (Iran) from 2005 to 2013 were evaluated. Razi Hospital is one of the leading dermatologic clinical centers in Iran and patients come from a wide area of Iran.

The data which included demographic data (age and gender), the site of pemphigoid involvement (cutaneous lesion, oral mucosa, or both), pemphigoid type (BP, MMP, and PG), and blood groups $(\mathrm{A}, \mathrm{B}, \mathrm{AB}$, and $\mathrm{O}$ ) as well as Rh (positive or negative) were extracted from the patients' records. The patients without blood group and $\mathrm{Rh}$ history in their records were excluded from the study. The final number of patients in the data frameset was 159 . Totally, 152 control patients were randomly chosen from healthy people who were referred to Razi Hospital, and their blood groups as well as Rh were collected from their medical records.
This study has been independently reviewed and approved by ethics committee of Shahid Beheshti University of Medical Sciences; also, this research has been conducted in full accordance with the world medical association Declaration of Helsinki. We confirm that patients' information remained confidential and data was anonymized and deidentified prior to analysis.

The data were analyzed with SPSS (Statistical package for Social Sciences 19; SPSS 19, Chicago, IL, USA). The frequency of blood groups and $\mathrm{Rh}$ of pemphigoid patients as well as control group were determined. The chi-square test was used to compare qualitative variables, and the logistic regression test was used to examine the relationship between blood groups and Rh in pemphigoid patients and control group. $P$ value of $<0.05$ was considered statistically significant.

\section{Results}

In pemphigoid patients, 7 cases $(2.3 \%)$ had MMP, 146 cases (46.9\%) had BP, and 6 cases (1.9\%) had PG (Table 1$)$.

Over $14 \%$ of MMP patients had only oral involvement and the coincidence of oral and cutaneous lesions was seen in $71.4 \%$ of patients while in BP group there was no case with only oral involvement. However, cutaneous involvement without oral lesions was common in BP patients. There was no oral involvement in cases with PG (Table 2).

Distribution of blood group and $\mathrm{Rh}$ in different types of pemphigoid and control group is shown in Table 3. However, because of the limited number of MMP and PG patients, statistical comparisons were only completed with BP cases. Blood group $\mathrm{O}$ was found in nearly a third of all BP patients $(n=48,32.9 \%)$ and controls $(n=58,38.2 \%)$. Similarly, about a third of cases $(n=45,30.8 \%)$ and controls $(n=52,34.2 \%)$ had blood group A. There was no significant difference between various blood groups in patients with BP and the control group $(P=0.46)$. Also, $124(84.9 \%)$ patients were Rh positive and $22(15.1 \%)$ were Rh negative. In the control group, 131 patients $(86.2 \%)$ were $\mathrm{Rh}$ positive and 21 cases (13.8\%) were Rh negative. Chi-square test results showed no significant differences in the distribution of Rh between BP and control group $(P=0.76)$. In addition, logistic regression demonstrated that older females significantly had higher risk of developing BP disease $(P=0.018$ and 0.0001, 
TABLE 3: Distribution of blood group and Rh in different pemphigoid types and control group.

\begin{tabular}{|c|c|c|c|c|c|c|c|c|c|c|c|c|}
\hline \multirow{2}{*}{ Blood group } & \multicolumn{2}{|l|}{ A } & \multicolumn{2}{|l|}{$\mathrm{B}$} & \multicolumn{2}{|l|}{$\mathrm{O}$} & \multicolumn{2}{|l|}{$\mathrm{AB}$} & \multicolumn{2}{|c|}{$\mathrm{Rh}+$} & \multicolumn{2}{|c|}{$\mathrm{Rh}-$} \\
\hline & Number & $\%$ & Number & $\%$ & Number & $\%$ & Number & $\%$ & Number & $\%$ & Number & $\%$ \\
\hline Mucous membrane pemphigoid & 3 & 42.9 & 2 & 28.6 & 2 & 28.6 & 0 & 0.0 & 5 & 71.4 & 2 & 28.6 \\
\hline Bullous pemphigoid & 45 & 30.8 & 40 & 27.4 & 48 & 32.9 & 13 & 8.9 & 124 & 84.9 & 22 & 15.1 \\
\hline Pemphigoid gestationis & 3 & 50.0 & 2 & 33.3 & 1 & 16.7 & 0 & 0.0 & 5 & 83.3 & 1 & 16.7 \\
\hline Control group & 52 & 34.2 & 32 & 21.1 & 58 & 38.2 & 10 & 6.6 & 131 & 86.2 & 21 & 13.8 \\
\hline
\end{tabular}

TABLE 4: Relationship between blood groups and Rh in pemphigoid patients with regard to age and sex (logistic regression).

\begin{tabular}{lccccc}
\hline Variables & $B$ & SE & $P$ value & OR & LI \\
\hline Sex (male) & -0.623 & 0.0262 & 0.018 & 0.0536 & 0.0321 \\
Age & 0.0059 & 0.0009 & 0.0001 & 1.061 & 1.043 \\
Blood group O* & & & 0.0484 & & 0.89 \\
Blood group A & 0.0218 & 0.0312 & 0.0485 & 1.244 & 0.0674 \\
Blood group B & 0.0507 & 0.0342 & 0.0139 & 1.660 & 0.0848 \\
Blood group AB & 0.0427 & 0.0537 & 0.0380 & 1.603 & 0.0559 \\
RH+ & -0.0235 & 0.0390 & 0.0547 & 0.0795 & 0.0368 \\
Constant & -3.374 & 0.0669 & 0.000 & 0.0034 & 4.29 \\
\hline B & & & & 1.69 \\
\hline
\end{tabular}

$B$ : estimate.

SE: standard error.

OR: odds ratio, $\operatorname{EXP}(B)$.

$\mathrm{CI}$ : confidence interval for odds ratio.

$*$ : reference blood group.

resp.); in other words, the odds of having disease in females are twice compared to males. Increasing a year of age will increase the chance of disease by $6 \%$. However, there was not any significant relationship among different blood groups (Table 4). We could not do statistical examination between cutaneous and oral involvement due to limited number of patients that have only oral involvement.

\section{Discussion}

This study for the first time examined the relationship between pemphigoid diseases and $\mathrm{ABO}$ and $\mathrm{Rh}$ blood groups in 159 patients with various types of pemphigoid and 152 healthy controls in Iranian population. Statistical analyses did not show any significant relationship. This study collected 146 cases of BP, 7 cases of MMP, and 6 cases of PG and studied genders, ages of disease onset, and involvement of either skin or oral mucosa. There are some studies that evaluate the relationship of various blood groups in a variety of diseases $[9,11-22]$, such as pemphigus vulgaris [11-15] and oral cancer $[9,16-18]$.

In 1969, Altobella [23] assessed the relation between blood groups and various dermatoses and concluded that $60 \%$ of pemphigus vulgaris patients had blood group $\mathrm{O}$; however, no comparison was done with the control group. Also, the result of Grob and Inderbitzin study [17] indicated that vulgaris pemphigus is more frequent among people with blood group O. Shahkar et al. [14] investigated blood groups of 56 Iranian patients suffering from pemphigus. According to the results of recent surveys, no significant relation has been observed between blood groups $\mathrm{ABO}$ and vulgaris pemphigus. Valikhani et al. [11] did not find any significant relationship between blood groups $\mathrm{ABO}$ or blood factor $\mathrm{Rh}$ with subgroups of pemphigus in Iranian population. Also, Tirado-Sánchez and Ponce-Olivera [15] concluded that there is no relation between blood groups $\mathrm{ABO}$ and $\mathrm{Rh}$ among pemphigus patients and healthy people.

Frequency of blood groups in various groups of cancer patients in northern India [16] showed that, compared with the control group, people with blood group A had a higher rate of SCC; and Mortazavi et al. [9] reported that SCC was more prevalent among people with blood group $\mathrm{B}$, and it was less prevalent among those with blood group $\mathrm{AB}$ than among healthy people.

In the present study, most of patients, as well as the control group, had blood group O (32.9\% and 38.2\%, resp.). In line with our study, Mortazavi et al. [9] reported that blood group $\mathrm{O}$ is the most common blood group in Iranian population. Based on the present survey, $84.9 \%$ of the patients had $\mathrm{Rh}+$ and $15.4 \% \mathrm{Rh}-$. In the control group, $86.2 \%$ had $\mathrm{Rh}+$ and $13.8 \% \mathrm{Rh}-$. No significant difference was noticed in pemphigoid patients and the control group in distribution of Rh. No previous research has ever evaluated the relation between positive and negative $\mathrm{Rh}$ with pemphigoid.

Moreover, there are some reports about associations between susceptibility to certain diseases and Lewis antigen and secretor status phenotype based on linkage among $\mathrm{ABH}$, Lewis blood group system, and secretor status. For instance, in 2014, Shahidi-Dadras and Golfeshan [24] evaluated Lewis blood group antigens and secretor status in pemphigus vulgaris. They showed that Le/b-negative nonsecretor individuals are more susceptible to pemphigus vulgaris. Also, 
in 2004, Xuan et al. [25] evaluated the association of Lewis blood group expression with ocular cicatricial pemphigoid (OCP) and reported that the anti-Le (a) and anti-Le (b) immunoreactivity of epithelial and goblet cells was considerably decreased, and more than $40 \%$ of OCP patients had the nonsecretor phenotype, which was significantly higher than the healthy population. They concluded that OCP might be associated with a nonsecretor phenotype. However, in the present study we did not evaluate OCP phenotype; MMP has several clinical variants or manifestations, and this study only included oral, cutaneous, and mixed type. This is a preliminary study for pemphigoid disease and evaluating Lewis antigens and nonsecretor phenotype in diffident types of pemphigoid disease is recommended for future studies.

\section{Conclusion}

From the data of this study, it can be concluded that there was no clear relation between blood group $\mathrm{ABO}$ and $\mathrm{Rh}$ group with type of pemphigoid disease. Considering the fact that there is a conflict among results of studies, a systematic review to find a clear relationship between $\mathrm{ABO}$ blood groups and autoimmune disease is recommended for future studies.

\section{Competing Interests}

The authors declare that there are no competing interests regarding the publication of this paper.

\section{Acknowledgments}

This Study was done with close cooperation of Oral Medicine Department of Shahid Beheshti University of Medical Science. The authors would like to thank Professor Marc Tennant and Professor Estie Kruger of the University of Western Australia for assistance and advice with this project.

\section{References}

[1] B. Neville, L. Damm, S. Allen, and I. N. Bouquet, Oral and Maxillofacial Pathology, WB Saunders, Philadelphia, Pa, USA, 3rd edition, 2016.

[2] M. A. Weinberg and T. E. Abitbol, "Pemphigus vulgaris: gingival involvement: a case report," Annals of Dentistry, vol. 54, no. 1-2, pp. 8-13, 1995.

[3] W. M. Watkins, "The ABO blood group system: historical background," Transfusion Medicine, vol. 11, no. 4, pp. 243-265, 2001.

[4] G. N. Kolmakova and L. L. Kononova, "The prevalence of ABO blood groups among persons of native nationality in Buryatia," Sudebno-Meditsinskaia Ekspertiza, vol. 42, no. 2, pp. 15-16, 1999.

[5] A. C. Koregol, M. Raghavendra, S. Nainegali, N. Kalburgi, and S. Varma, "ABO blood groups and Rhesus factor: an exploring link to periodontal diseases," Indian Journal of Dental Research, vol. 21, no. 3, pp. 364-368, 2010.

[6] G. Garratty, "Relationship of blood groups to disease: do blood group antigens have a biological role?" Revista Médica del Instituto Mexicano del Seguro Social, vol. 43, pp. 113-121, 2005.
[7] G. Garratty, "Blood groups and disease: a historical perspective," Transfusion Medicine Reviews, vol. 14, no. 4, pp. 291-301, 2000.

[8] A. Tirado-Sánchez and R. M. Ponce-Olivera, "Lack of relationship between blood groups and clinical outcome (body surface area affected) in patients with pemphigus vulgaris," Indian Journal of Dermatology, vol. 57, no. 5, pp. 411-412, 2012.

[9] H. Mortazavi, S. Hajian, E. Fadavi, S. Sabour, M. Baharvand, and S. Bakhtiari, "ABO blood groups in oral cancer: a first casecontrol study in a defined group of Iranian patients," Asian Pacific Journal of Cancer Prevention, vol. 15, no. 3, pp. 1415-1418, 2014.

[10] L. S. Krain, P. I. Terasaki, V. D. Newcomer, and M. R. Mickey, "Increased frequency of HL-A10 in pemphigus vulgaris," Archives of Dermatology, vol. 108, no. 6, pp. 803-805, 1973.

[11] M. Valikhani, S. Kavand, S. Toosi, G. Kavand, and M. Ghiasi, "ABO blood groups, rhesus factor and pemphigus," Indian Journal of Dermatology, vol. 52, no. 4, pp. 176-178, 2007.

[12] D. Sirois, J. E. Leigh, and T. P. Sollecito, "Oral pemphigus vulgaris preceding cutaneous lesions: recognition and diagnosis," Journal of the American Dental Association, vol. 131, no. 8, pp. 1156-1160, 2000.

[13] M. Franchini and G. M. Liumbruno, "ABO blood group: old dogma, new perspectives," Clinical Chemistry and Laboratory Medicine, vol. 51, no. 8, pp. 1545-1553, 2013.

[14] H. Shahkar, M. K. Fallahzadeh, and M. R. Namazi, "ABO blood groups and pemphigus vulgaris: no relationship," Acta Dermatovenerologica Alpina, Pannonica et Adriatica, vol. 19, no. 1, pp. 49-51, 2010.

[15] A. Tirado-Sánchez and R. M. Ponce-Olivera, "ABO and Rhesus blood groups and their non-existent relationship with pemphigus vulgaris," Acta Dermatovenerologica Alpina, Pannonica et Adriatica, vol. 19, no. 3, pp. 47-48, 2010.

[16] K. Akhtar, G. Mehdi, R. Sherwanj, and L. Ahmad Sofi, "Relationship between various cancers and ABO blood groups-a northern India experience," Internet Journal of Pathology, vol. 13, no. 1, pp. 11-16, 2010.

[17] P. J. Grob and T. M. Inderbitzin, "Pemphigus antigen and blood group substances A and B," Journal of Investigative Dermatology, vol. 49, no. 3, pp. 285-287, 1967.

[18] B. F. Jaleel and R. Nagarajappa, "Relationship between ABO blood groups and oral cancer," Indian Journal of Dental Research, vol. 23, no. 1, pp. 7-10, 2012.

[19] M. R. Jalali Nadoushan, M. Hashemi, and N. Valaei, "Role of $\mathrm{ABO}$ blood groups as prognostic factors in primary breast cancer," Journal of Zanjan University of Medical Sciences, vol. 10, pp. 17-21, 2002.

[20] S. Sharif, N. Anwar, T. Farasat, and S. Naz, "ABO blood group frequency in ischemic heart disease patients in Pakistani population," Pakistan Journal of Medical Sciences, vol. 30, no. 3, pp. 593-595, 2014.

[21] S. Vahabi and M. Aslani, "Relationship between periodontal diseases and $\mathrm{ABO}$ blood groups and $\mathrm{Rh}$ system in pregnant women," Iranian Journal of Obstetrics, Gynecology and Infertility, vol. 15, no. 42, pp. 7-12, 2013.

[22] S. M. Kashfi, A. Khani Jeihooni, R. Afshariani, H. R. Tabatabaei, and M. Yazdankhah, "Frequency distribution of blood groups in diabetic patients and non diabetic patients in Shiraz Nader Kazemi clinic and the relationship between blood groups and diabetes (2010-2011)," Journal of Fasa University of Medical Sciences, vol. 2, no. 4, pp. 297-302, 2010. 
[23] L. Altobella, "Observations on the relationship between blood groups and various dermatoses," Archivio Italiano di Dermatologia, Venereologia, e Sessuologia, vol. 35, no. 4, pp. 319-326, 1969.

[24] M. Shahidi-Dadras and A. Golfeshan, "Evaluation of Lewis blood group antigens and secretor status in pemphigus vulgaris," Clinical and Experimental Dermatology, vol. 41, no. 1, pp. 16-20, 2016.

[25] T. H. Xuan, A. M. Bron, H. Robin, P. d'Athis, and J. Bara, "Blood group related antigens in ocular cicatricial pemphigoid," British Journal of Ophthalmology, vol. 88, no. 10, pp. 1247-1251, 2004. 


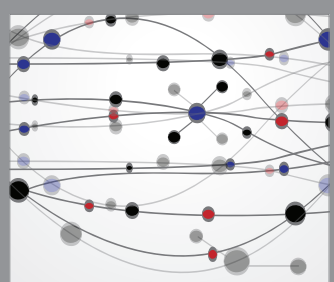

The Scientific World Journal
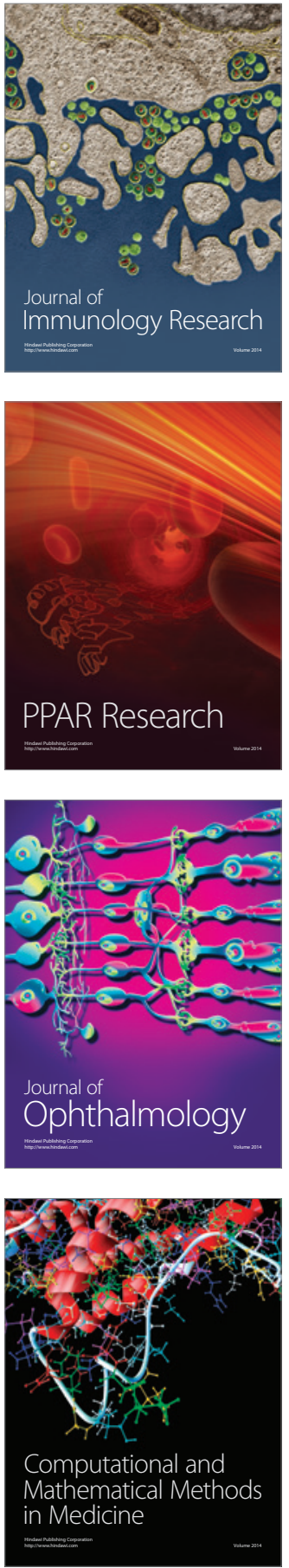

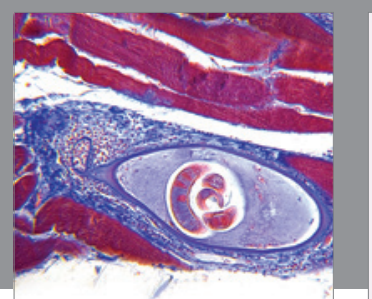

Gastroenterology Research and Practice

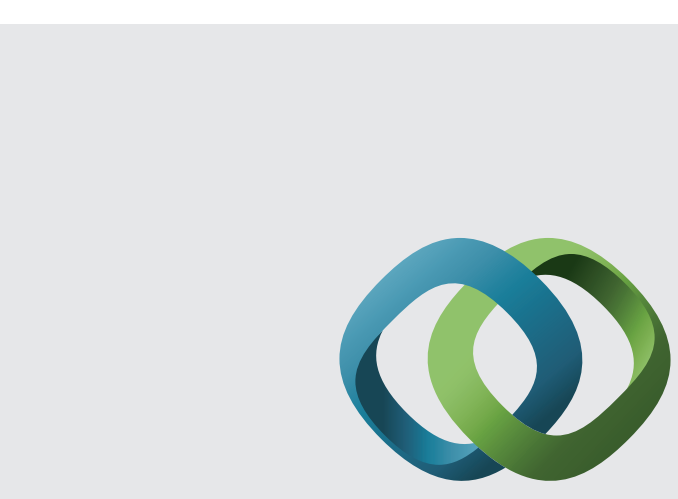

\section{Hindawi}

Submit your manuscripts at

http://www.hindawi.com
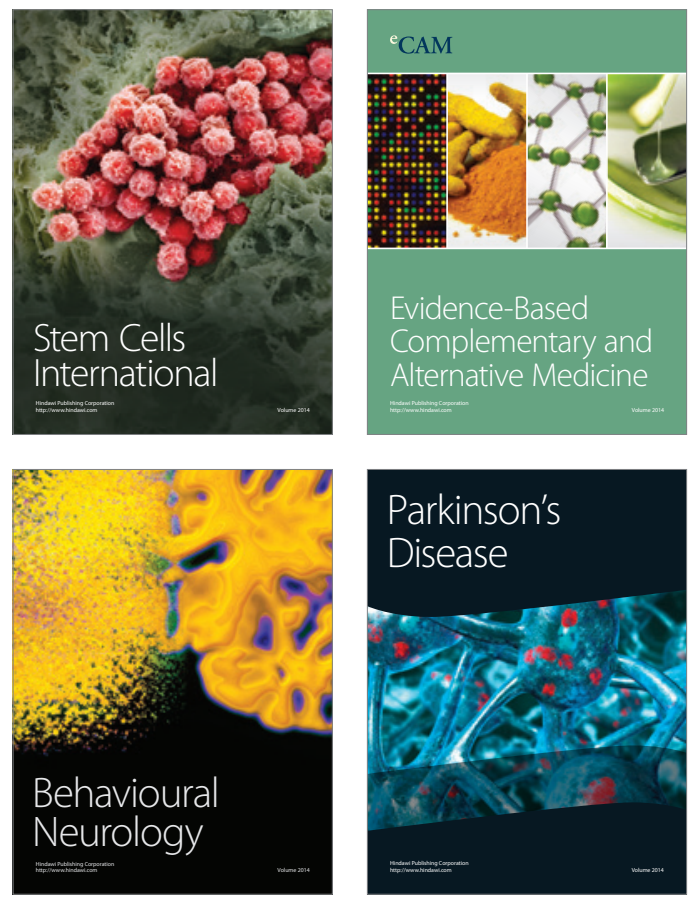
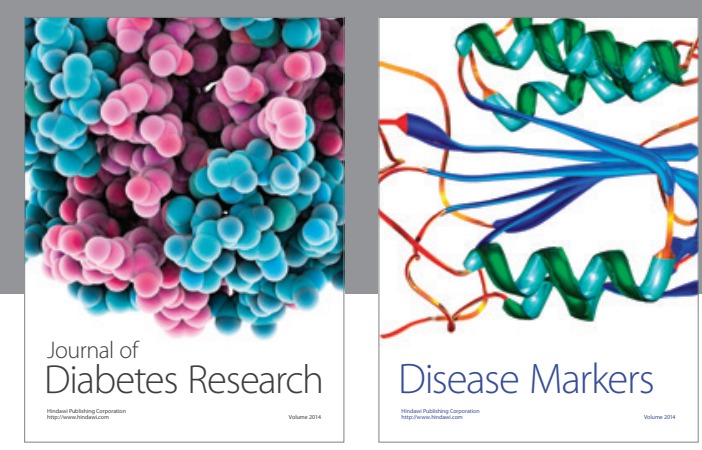

Disease Markers
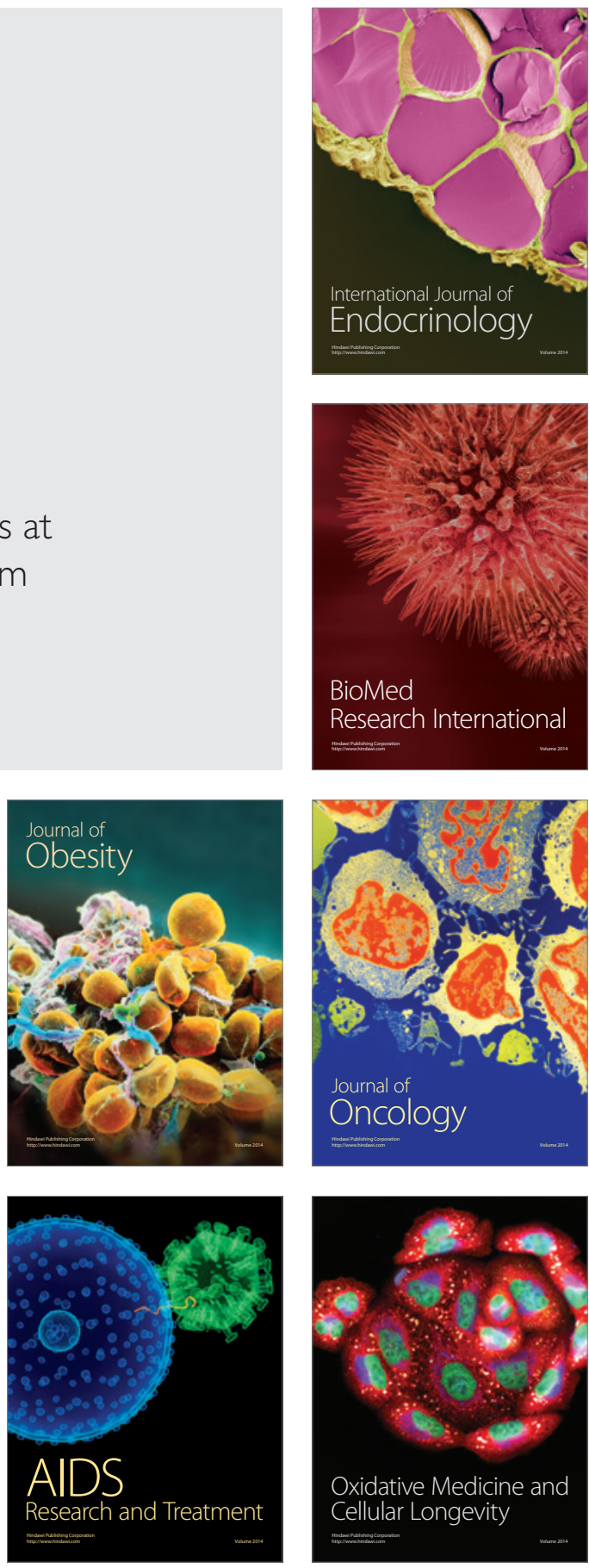